\title{
Penyuluhan Manajemen dan Pengembangan Usaha Agroindustri Pengolahan Sagu di Desa Gogok Darussalam
}

\author{
Septina Elida ${ }^{1 *}$, Sri Ayu Kurniati ${ }^{1}$, Sisca Vaulina ${ }^{1}$, Darus ${ }^{1}$
}

1Program Studi Agribisnis, Fakultas Pertanian, Universitas Islam Riau, Jalan Kaharuddin Nasution 113, Pekanbaru, Riau, Indonesia - 28284

*Penulis koresponden: septinaelida@agr.uir.ac.id

\section{Info Artikel}

\section{Riwayat :}

Dikirim 1 Mei 2020

Diterima 10 Mei 2020

Dipublikasi 13 Mei 2020

\section{Kata Kunci :}

Agroindustri

Nilai tambah

Pendapatan masyarakat

Pengembangan

Sagu

\begin{abstract}
Abstrak
Kabupaten Kepulauan Meranti sebagian besar masyarakatnya bermatapencaharian sebagai petani yang mengusahakan berbagai jenis tanaman, khususnya tanaman pangan. Selain melakukan kegiatan produksi atau usahatani bahan pangan, usaha yang banyak dilakukan masyarakat adalah pengolahan atau agroindustri sagu. Produk olahan sagu yang banyak dihasilkan adalah bermacam-macam produk makanan seperti mie sagu, sagu rendang, sagu lemak, kerupuk sagu, dan lainnya. Namun masih banyak usaha agroindustri sagu yang manajemen atau pengelolaan usahanya masih tradisional sehingga produktivitas usaha menjadi rendah. Kegiatan pengabdian kepada masyarakat dilakukan oleh tim Dosen Fakultas Pertanian Universitas Islam Riau di Desa Gogok Darussalam Kecamatan Tebing Tinggi Barat Kebupaten Kepulauan Meranti pada tanggal 25 Agustus 2018. Tema Kegiatan adalah penyuluhan manajemen dan pengembangan usaha agroindustri pengolahan sagu. Sehingga pengusaha agroindustri sagu memiliki kemampuan dan dapat membaca peluang usaha yang memiliki potensi untuk memproduksi produk unggulan yang berkualitas dan mampu memberikan nilai tambah produk sekaligus peningkatan pendapatan masyarakat.
\end{abstract}

\section{PENDAHULUAN}

Desa Gogok Darussalam merupakan salah satu desa yang termasuk dalam wilayah Kecamatan Tebing Tinggi Barat Kabupaten Kepulauan Meranti, dimana sebagian besar masyarakatnya bermatapencaharian sebagai petani, baik petani karet, sagu ataupun jenis tanaman lainnya. Daerah ini cocok dengan kondisi ideal untuk tumbuhnya sagu (Bintoro, Nurulhaq, Pratama, Ahmad, \& Ayulia, 2018; Haryanto \& Pangloli, 1992). Masyarakat mengusahakan berbagai jenis tanaman, khususnya tanaman pangan, umumnya adalah untuk dikonsumsi sendiri. Selain melakukan kegiatan produksi atau usahatani bahan pangan, usaha yang banyak dilakukan masyarakat adalah pengolahan atau agroindustri sagu (Singhal et al., 2008). Produk olahan sagu yang banyak dihasilkan diantaranya bermacam-macam produk makanan seperti mie sagu, sagu rendang, sagu lemak, kerupuk sagu, dan lainnya. Agroindustri sagu ini umumnya adalah usaha turun temurun dari nenek moyang dan dianggap sebagai kearifan lokal yang tidak dapat dipisahkan dari kehidupan masyarakat.

Pemerintah daerah Kabupaten Kepulauan Meranti menjadikan sagu sebagai ikon khas daerah. Program pengembangan daerah yang dilakukan adalah OVOP (One Village One 
Product) atau satu desa satu produk, yaitu pengembangan potensi daerah untuk menghasilkan produk unggulan yang khas dan unik dengan memanfaatkan sumber daya lokal. Landasan hukum program OVOP ini adalah Inpres No. 6 tahun 2007 tentang Percepatan Sektor Riil dan Pembangunan Usaha Kecil Mikro dan Menengah. Diketahui terdapat 67 kilang sagu rakyat yang menghasilkan sagu basah dan tepung sagu dengan rata-rata jumlah tenaga kerja tiap kilang adalah 4-7 orang. Sementara untuk produk pati sagu beroperasi lebih dari 113 pengusaha dengan rata-rata tenaga kerja tiap usaha adalah 2-6 orang.

Usaha agroindustri sagu merupakan usaha yang menguntungkan jika diusahakan dengan baik dan benar serta memiliki potensi besar untuk dikembangkan sebagai komoditas andalan. Agroindustri sagu di Desa Gogok lebih banyak diusahakan oleh industri dalam skala kecil dan rumah tangga dengan penggunaan peralatan dan teknologi yang masih sederhana. Untuk memperoleh pendapatan yang tinggi maka diperlukan manajemen usaha yang efektif dan efisien melalui penerapan teknologi sehingga produsen sagu senantiasa dapat berproduksi dan pengembangan usaha berkelanjutan sesuai harapan yang diinginkan.

Namun masih banyak usaha agroindustri sagu yang manajemen atau pengelolaan usahanya masih tradisional sehingga produktivitas usaha menjadi rendah (Timisela, 2006). Pengusaha agroindustri sagu dalam menjalankan usahanya biasanya hanya sekedar memproduksi dan memasarkan tanpa perencanaan jangka panjang. Padahal perencanaan yang matang akan membawa pengusaha pada kemampuannya untuk mengembangkan usaha menjadi lebih besar lagi.

Oleh karena itu perlu dilakukan penyuluhan guna meningkatkan kemampuan dan kompetensi pengusaha dalam manajemen dan pengembangan usaha. Sehingga pengusaha agroindustri sagu dapat membaca peluang usaha yang memiliki potensi untuk memproduksi produk unggulan yang berkualitas dan mampu memberikan nilai tambah produk sekaligus peningkatan pendapatan masyarakat.

Sagu di Desa Gogok Darussalam merupakan komoditas unggulan daerah dan kearifan lokal yang harus dilestarikan. Saat ini produksi sagu diusahakan melalui agroindustri dalam upaya peningkatan pendapatan masyarakat. Berbagai upaya mendorong peningkatan perekonomian adalah dengan pengolahan sagu menjadi berbagai produk olahan yang menghasilkan nilai ekonomis seperti mie sagu, sagu rendang, sagu lemak, kerupuk sagu, dan sebagainya.

Berdasarkan informasi awal diketahui bahwa masyarakat kurang termotivasi untuk melakukan kegiatan agroindustri ini. Beberapa hal yang dianggap sebagai kendala adalah keterbatasan modal dan minimnya kemampuan dalam manajemen usaha, baik manajemen bahan baku, proses produksi, minimnya tenaga kerja terampil, kurangnya penerapan teknologi hingga pemasaran hasil produksi, yang pada akhirnya mempengaruhi pengusaha untuk mengembangkan usaha agroindustri sagu.

Target yang ingin dicapai pada pengabdian manajemen dan pengembangan usaha di Desa Gogok Darussalam ini adalah peningkatan jumlah produksi olahan sagu dibandingkan periode sebelumnya, karyawan disiplin dalam bekerja, karyawan memahami tahapan kerja yang menjadi tanggung jawabnya, lebih banyak penggunaan peralatan dan mesin modern, memiliki catatan biaya produksi dan tersedianya aliran pembuangan limbanh yang aman terhadap lingkungan.

\section{METODE PELAKSANAAN}

Pengabdian masyarakat ini dilaksanakan di Desa Gogok Darussalam Kecamatan Tebing Tinggi Barat Kabupaten Kepulauan Meranti. Waktu penyuluhan dilakukan pada hari Sabtu tanggal 25 Agustus 2018. 
Pelaksanaan penyuluhan dilakukan dalam menyelesaikan program pengabdian ini adalah penyuluhan kepada pengusaha agroindustri sagu di Desa Gogok Darussalam mengenai manajemen dan pengembangan usaha agroindustri. Metode penyuluhan disesuaikan dengan tujuan pengabdian yaitu:

1. Memberikan pengetahuan kepada pengusaha agroindustri pengolahan sagu dalam bentuk penyuluhan mengelola usaha agar dapat tumbuh dan berkembang lebih baik lagi.

2. Memberikan pemahaman yang aplikatif kepada pengusaha agroindustri pengusaha sagu dalam hal manajemen dan pengembangan usaha secara efektif dengan menggunakan sistem informasi dan teknologi

\section{HASIL DAN PEMBAHASAN}

Pelaksanaan kegiatan penyuluhan Manajemen dan Pengembangan Usaha Agroindustri Pengolahan Sagu Di Desa Gogok Darussalam Kecamatan Tebing Tinggi Barat Kabupaten Kepulauan Meranti telah terlaksana, setelah dilakukan beberapa kali koordinasi dengan pihak kecamatan tentang peserta penyuluhan yang menjadi target penyuluhan, waktu pelaksanaan serta tempat yang relevan sebagaimana tertuang dalam dokumen rencana kegiatan.

Kegiatan dilakukan dengan pola penyampaian materi yang dilaksanakan di rumah Ketua RT Desa Gogok Darussalam Kecamatan Tebing Tinggi Barat. Kegiatan penyuluhan dilakukan mulai dari pukul 08.30 WIB sampai dengan pukul 13.00 WIB. Peserta penyuluhan adalah pengusaha agroindustri pengolahan sagu yang ada di Kecamatan Tebing Tinggi Barat, yang berjumlah 20 orang (Gambar 1). Pemberian materi penyuluhan dalam bentuk lembaran fotocopy kepada peserta dilakukan sebelum acara penyuluhan dimulai. Hal ini dilakukan bertepatan dengan pengisian daftar hadir oleh masing-masing peserta penyuluhan. Pemberian modul dimaksudkan agar peserta penyuluhan memahami materi yang akan disampaikan.

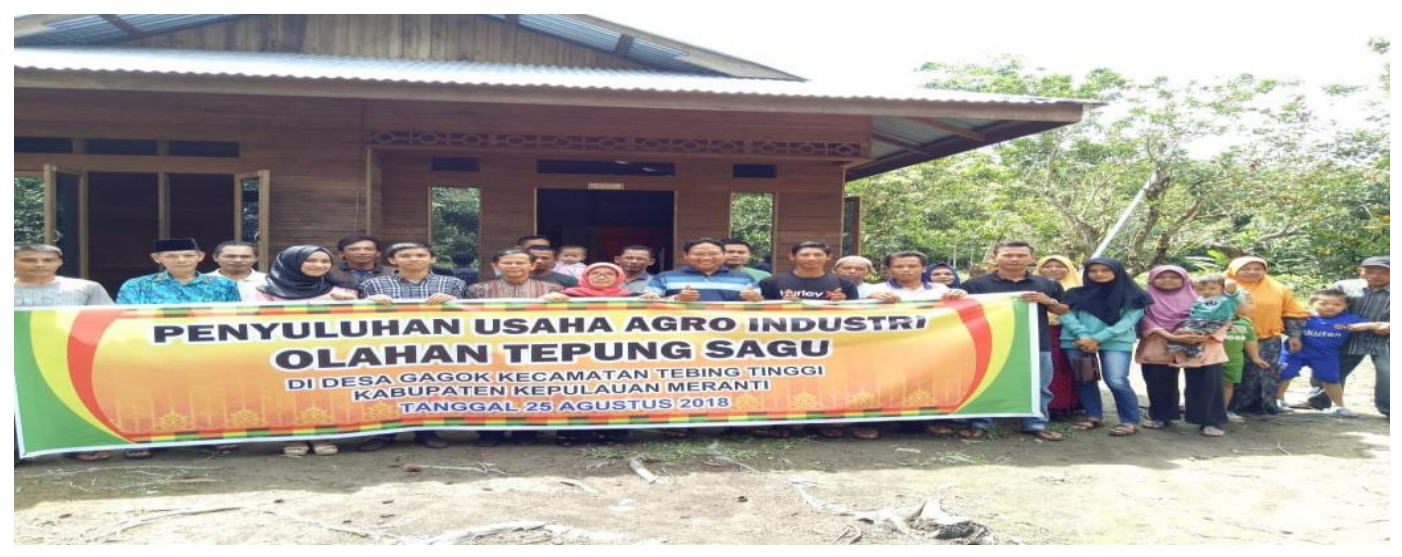

Gambar 1. Foto Bersama tim pengabdian dan masyarakat desa.

Setelah peserta hadir di dalam ruangan maka acara penyuluhan dimulai. Acara dibuka oleh Ketua RT dan Ketua RW Desa Gogok Kecamatan Tebing Tinggi Barat dan dilanjutkan oleh pengantar dan pengarahan dari ketua pelaksana. Acara penyuluhan juga dihadiri oleh pemudapemuda karang taruna Kecamatan Tebing Tinggi Barat. Penyampaian materi dilakukan oleh perwakilan beberapa dosen Fakultas Pertanian UIR yang mengikuti kegiatan pengabdian masyarakat.

Penyampaian materi penyuluhan dilakukan dengan cara pemaparan dan diskusi serta tanya jawab dengan menggunakan alat bantu infokus. Materi yang disampaikan berkaitan dengan agroindustri sagu, manajemen dan pengembangan usaha agroindustri sagu. Setelah 
pemaparan materi, kegiatan selanjutnya adalah diskusi terbuka dan berbagi pengalaman antara pemateri dan peserta penyuluhan. Agar tercipta suasana yang kondusif, tertib dan demi kelancaran acara penyuluhan ini maka tiap materi penyuluhan yang disampaikan oleh narasumber didampingi oleh moderator sebagai pemandu acara.

Penyuluhan dalam rangka kegiatan pengabdian kepada masyarakat cukup memuaskan, baik bagi peserta penyuluhan maupun tim penyuluhan. Pemahaman peserta penyuluhan terlihat pada saat diskusi dan tanya jawab peserta dengan tim penyuluh. Sebagian besar peserta mampu menyerap dan memahami materi yang disampaikan. Secara umum dapat dikatakan bahwa peserta mulai mengetahui dan memahami dengan baik tentang manajemen dan pengembangan usaha agroindustri sagu dengan baik dan benar.

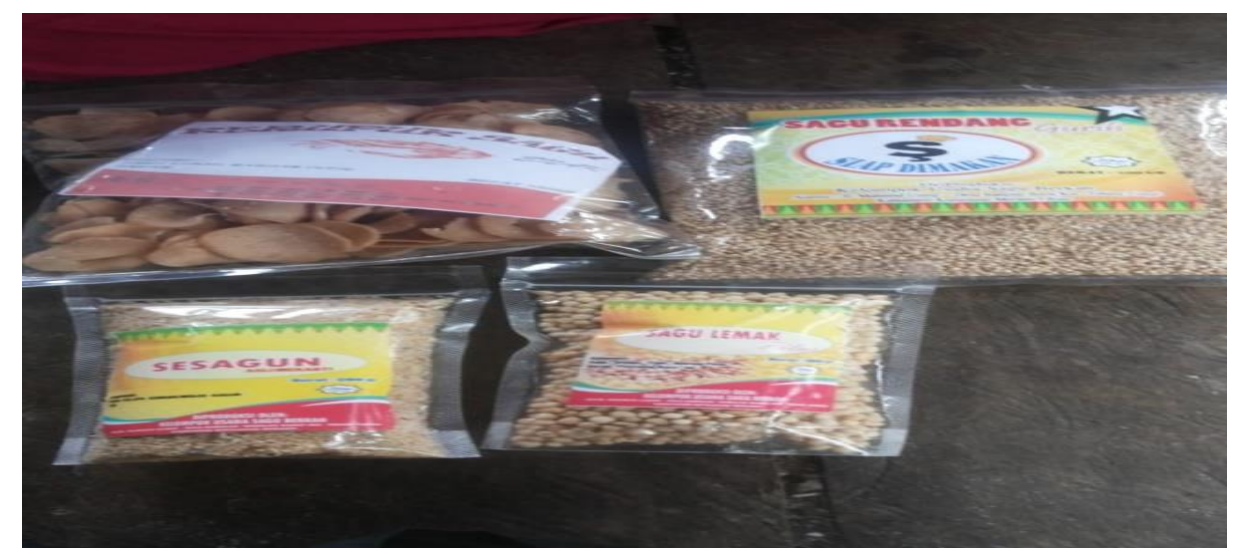

Gambar 2. Produk agroindusti pengolahan sagu

Pengamatan secara mendalam dan komprehensif serta evaluasi pelaksaan kegiatan penyuluhan menjadi tolok ukur untuk mengetahui capaian peningkatan pengetahuan, pemahaman, dan kompetensi peserta khusunya pada manajemen dan pengembangan usaha agroindustri sagu. Kegiatan monitoring terhadap partisipasi aktirf peserta penyuluhan dimulai sejak diawal acara hingga penutupan kegiatan penyuluhan. Pada tahap ini setiap materi yang disampaikan oleh narasumber direspon aktif oleh peserta dengan perhatian yang optimal. Begitupun pada alokasi waktu saat diskusi, dimana kearifan peserta juga dimonitoring.

Sebagian besar peserta sangat aktif mengajukan pertanyaan bahkan sampai berulang ulang sesuai dengan materi yang disampaikan dan masalah yang dihadapi dalam menjalankan usaha agroindustri pengolahan sagu. Pada berbagai pertanyaan yang diberikan, narasumber berupaya memberikan jawaban dalam bentuk contoh dan memberikan solusi praktis berkaitan dengan masalah yang dialami dan dihadapi oleh pengusaha dengan menggunakan bahasa yang mudah dipahami oleh peserta penyuluhan.

Penyelenggaraan kegiatan penyuluhan manajemen dan pengembangan usaha agroindustri pengolahan sagu di Kecamatan Tebing Tinggi Barat dianggap peserta telah berjalan dengan baik. Alokasi waktu yang disediakan dan target penyuluhan dapat dicapai sesuai dengan yang diharapkan. Hasil penilaian para peserta secara umum terhadap keseluruhan pelaksanaan penyelenggaraan kegiatan adalah cukup baik. Fasilitas yang digunakan sangat memadai dan membantu kegiatan penyuluhan, dan pengorganisasian tim pelaksana sebagai narasumber maupun fasilitator berjalan dengan baik.

Pengorganisasian internal pengusaha agroindustri pengolahan sagu sepenuhnya dilakukan oleh pihak kecamatan antara lain pemilihan peserta, penyampaian undangan, persiapan ruangan dan peralatan. Untuk akomodasi peralatan peragaan, konsumsi, dan transportasi dipersiapkan oleh tim pelaksana kegiatan penyuluhan. Beberapa alat peraga yang 
dibutuhkan antara lain laptop, LCD, proyektor, handout, buku buku pedoman dan jurnal yang relevan.

Berdasarkan penilaian peserta diperoleh indikasi secara umum peserta menyampaikan bahwa para narasumber dan fasilitator dalam menyampaikan materi, baik substansi maupun pengalaman empiris selaku pengusaha agroindustri pengolahan sagu, cukup baik dan bermanfaat. Tim pelaksana penyuluhan sangat menerima saran dan masukan dari para peserta. Menurut mereka kegiatan bertukar pikiran seperti inilah yang dibutuhkan demi kemajuan perkembangan usaha agroindustri pengolahan sagu di Kecamatan Tebing Tinggi Barat.

\section{KESIMPULAN}

Beberapa hal yang dapat disimpulkan dari pelaksanaan kegiatan pengabdian masyarakat ini antara lain:

1. Kegiatan penyuluhan mananjemen dan pengembangan usaha di Desa Gogok Darussalam Kecamatan Tebing Tinggi Barat diselenggarakan dengan baik dan berjalan lancar sesuai dengan rencana yang telah disusun. Kegiatan ini mendapat sampbutan yang sangat baik terbukti dari keaktifan peserta mengikuti acara mulai dari awal hingga kegiatan penyuluhan berakhir.

2. Pengetahuan masyarakat khususnya pengusaha agroindustri pengolahan sagu tentang manajemen dan pengembangan usaha, secara umum meningkat

3. Peserta masih menginginkan adanya diskusi ulang pada kesempatan lain mengingat waktu diskusi untuk tiap materi dianggap terlalu singkat, meskipun materi penyuluhan dianggap culup baik oleh peserta

\section{UCAPAN TERIMA KASIH}

Terima kasih kepada Lembaga Penelitian dan Pengabdian Kepada Masyarakat (LPPM) Universitas Islam Riau yang telah memberikan dukungan dana terselenggaranya kegiatan ini melalu kontrak no. 484/PkM/KONTRAK/LPPM-UIR/10-2018

\section{DAFTAR PUSTAKA}

Bintoro, M. H., Nurulhaq, M. I., Pratama, A. J., Ahmad, F., \& Ayulia, L. (2018). Growing area of sago palm and its environment. In Sago Palm (pp. 17-29). Springer, Singapore.

Haryanto, B., \& Pangloli, P. (1992). Potensi dan pemanfaatan sagu. Kanisius. Yogyakarta, 140. Singhal, R. S., Kennedy, J. F., Gopalakrishnan, S. M., Kaczmarek, A., Knill, C. J., \& Akmar, P. F. (2008). Industrial production, processing, and utilization of sago palm-derived products. Carbohydrate Polymers, 72(1), 1-20.

Timisela, N. R. (2006). Analisis usaha sagu rumahtangga dan pemasarannya. Agroforestri. Fakultas Pertanian Unpatti Ambon, 1 (3), 57, 64. 